\title{
Implications of Non-invasive Mechanical Ventilation in Lung Transplantation. Old and New Frontiers?
}

\author{
Gema Tirado-Conde ${ }^{1}$, Marina Ortega Antelo ${ }^{1}$, José M Naranjo ${ }^{2}$ and Antonio M Esquinas ${ }^{3}$ \\ ${ }^{1}$ Clinical Management Unit of Respiratory Medicine, Complejo Hospitalario Universitario de Granada, Spain \\ ${ }^{2}$ Department of Thoracic Surgery and Lung Transplantation, Hospital Universitario Puerta de Hierro, Spain \\ ${ }^{3}$ Department of Intensive Care Unit, Hospital General Universitario Morales Meseguer, Spain
}

Submission: November 25, 2016; Published: January 05, 2017

*Corresponding author: Dr. Gema Tirado Conde, MD, PhD, Consultant and Chest Physician in Clinical Management Unit of Respiratory Medicine. Hospital Universitario "Virgen de las Nieves". Avda. de las Fuerzas Armadas, s/n. ZIP CODE: 18014; Granada, Spain, Tel: +34 956005002 ; +34645619550; E-mail: gtirado@separ.es

\begin{abstract}
As lung transplantation has become more successful, the selection criteria have broadened; however, some relative contraindications to lung transplantation are controversial. Some programs consider mechanical ventilation to be a major contraindication to lung transplantation because airway colonization with bacteria may lead to nosocomial infection and respiratory muscle deconditioning may necessitate prolonged postoperative ventilatory support. Non-invasive mechanical ventilation is accepted as a bridge to lung transplantation, but there is little evidence to support its use outside this setting. Use of non-invasive positive pressure ventilation (NPPV) has been reported as a means of avoiding orotracheal intubation in cases of respiratory failure, and in cases of refractory hypoxia; and several longitudinal randomised studies have shown its superiority over conventional ventilation.
\end{abstract}

Keywords: Non-invasive ventilation; Non-invasive positive pressure ventilation; Acute respiratory distress syndrome; Cystic fibrosis; Lung protective ventilation; Mechanical ventilation; Airway lesions; Tidal volume; Ventilator induced lung injury

\section{Introduction}

In 1909, Meltzer and Auer published a study on continuous breathing without respiratory movements obtained by introducing a continuous stream of air and anaesthetic vapour into the trachea [1]. This can be seen as the origin of mechanical ventilation, as it preceded the subsequent development of methods for applying intermittent positive pressure and orotracheal tubes with pilot balloon. In the last 30-40 years, important progress has been made due to better understanding of the Pathophysiology of breathing, the emergence of new specialists in intensive respiratory care, and technological development. Several alternatives breathing support strategies have been designed that have reduced the associated complications.

\section{Purpose of Ventilation}

The primary objective is to obtain adequate pulmonary gas exchange. The need for support may be due to $\mathrm{CO} 2$ retention (respiratory failure), insufficient oxygenation (hypoxemia) or a combination of the two. There are other secondary objectives, such as support in case of muscle fatigue, and to help lung damage repair by reopening alveoli and improving the ventilationperfusion ratio, thereby circumventing the need for high oxygen concentrations that can cause oxidative damage to the lungs.

Spontaneous breathing is controlled by the connection between central and peripheral chemoreceptor's and mechanoreceptors in the lung and chest wall. This system determines respiratory rate, respiratory volume, and inspiratory and expiratory time. During mechanical ventilation, however, this system is replaced by certain ventilator adjustments based on parameters such as tidal volume, respiratory rate, magnitude and duration of inspiratory flow and the inhalation-exhalation ratio. The need for a certain type of ventilatory support for a given patient depends on the mechanism, severity and expected duration of that patient's respiratory failure.

\section{Indications of Ventilation}

Mechanical ventilation is an intervention that enables adequate gas exchange during certain acute events. It is indicated 
in the following circumstances:

a) Insufficient alveolar ventilation, with elevated PCO2. Rapid elevation of PCO2 is accompanied by significant respiratory acidosis; a more gradual increase can be compensated and better tolerated. There is no clear cut-off $\mathrm{pH}$ value beyond which a patient requires ventilation. Zwillch suggested 7.30 [2], below which morbidity and mortality are significant.

b) Diminished or unstable ventilation: manifests as a slower respiratory rate or even apnoea. It occurs in situations such as head trauma, drug overdoses or cerebrovascular accidents. There is a risk of apnoea, so ventilation is indicated even when there is no hypercapnia.

c) Severe hypoxaemia, which does not resolve with the administration of oxygen through a mask.

d) Insufficient pulmonary expansion: can cause atelectasis and pneumonia. It can occur during general anaesthesia, trauma or acute restrictive pulmonary disease.

e) Insufficient respiratory muscle function: such as in Guillen-Barré syndrome.

f) Excessive respiratory effort: which the patient cannot maintain. During an acute disorder, it usually starts with tachypnoea.

\section{Complications of Mechanical Ventilation}

Complications can be due to the underlying condition, its severity, the intensive care setting and mechanical ventilation itself.

a. Altered ventilation-perfusion ratio: perfusion increases in dependent lung regions, while ventilation increases in the rest.

b. Reduced alveolar perfusion: high-pressure values in the airways, especially with hypovolaemia, can cause compression in the pulmonary capillaries, transforming functioning alveolar-capillary units into physiological dead spaces.

c. Altered circulation: as intra-thoracic pressure increases, venous return diminishes, which in turn diminishes cardiac output and renal perfusion. This is further aggravated in the case of hypovolaemia.

d. Liver and kidney dysfunction: the use of PEEP has been associated with reduced portal and renal flow rates, which can cause dysfunction in these organs.

e. Increased intracranial pressure: an increase in intrathoracic pressure causes reduced venous drainage from the head.

f. Gastric distension: due to swallowing air because of leaks around the balloon in patients with orotracheal intubation.

g. Altered acid-base balance: usually due to sub-optimal ventilator adjustment.

h. Air entrapment, dynamic hyperinflation and autoPEEP: when the expiratory flow is blocked, exhalation may not have completed before the next inhalation starts. Pulmonary volume and alveolar pressure, therefore, are still high at the end of the exhalation, resulting in the same physiological effects as excessive PEEP.

i. Barotrauma: manifest as pneumothorax, pneumomediastinum or subcutaneous emphysema. The cause is usually interstitial alveolar rupture, with subsequent dissection to the mediastinum or elsewhere.

j. Volutrauma (ventilator-induced lung damage): the precise mechanism is not clear, but it is associated with alveolar over distension.

k. Nosocomial pneumonia: from oropharyngeal germs.

l. Air way lesions: lesions caused during orotracheal intubation, tracheal stenosis, bronchoaspiration, and tracheal-oesophageal fistula.

m. Muscle weakness: due to long-term use of muscle relaxants.

n. Reduced oxygenation in ventilated patient: there are several causes, such as ventilator or circuit problems, unfavourable evolution of the patient's primary process, the onset of a new medical problem, or certain manoeuvres and interventions.

\section{Non-Invasive Positive Pressure Ventilation (NPPV)}

The use of continuous positive airway pressure (CPAP) in the airways was first suggested in 1981 to treat obstructive sleep apnoea [3]. The application of CPAP through a mask for this purpose was the first step in the development of NPPV for patients with chronic respiratory failure. Generally speaking, there are two NPPV techniques: positive pressure applied continuously to the airway throughout the respiratory cycle (CPAP); or positive pressure applied intermittently. In CPAP, breathing is spontaneous and generated solely by the respiratory muscles. Intermittent positive pressure systems, meanwhile, are applied in one of two ways:

a. pressure support ventilation, in which a certain pressure is applied to the airway during inhalation to improve spontaneous breathing. The respiratory rate is determined by the patient and the tidal volume by the amount of inspiratory support pressure and factors such as inspiratory and respiratory effort. It is activated either when system pressure decreases or flow increases;

b. bi-level positive airway pressure, which is similar to CPAP, but with pressure support. Inspiratory and expiratory 


\section{International Journal of Pulmonary \& Respiratory Sciences}

pressure can be adjusted and the ventilator switches from inhalation to exhalation when flow changes are detected.

The difference between inspiratory and expiratory pressure is the non-invasive pressure support. Positive pressure can be applied at the end of exhalation (PEEP) with either of these two methods. The success of NPPV largely depends on the patient's ability to cooperate and synchronise his or her breathing with the ventilator because, unlike invasive ventilation, the patient does not receive muscle relaxants. This type of ventilation was initially used in patients with neuromuscular disorders and chest wall diseases, subsequently extending its use to other disorders [4]. The use of NPPV was first described in 1989 to circumvent the need to intubate patients with acute respiratory failure [5] and it was subsequently described in COPD exacerbations [6] reducing ventilation time and duration of ICU admission, suggesting that NPPV could reduce ventilator-induced morbidity and the cost of COPD exacerbations. Subsequent studies of patients with COPD exacerbations [7,8] support the use of NPPV to circumvent orotracheal intubation.

Use of NPPV has also been described in acute respiratory failure due to causes other than COPD: in patients with acute decline due to restrictive thoracic diseases [9] hypoxemic respiratory failure without hypercapnia (pneumonia, ADRS, cardiogenic oedema) [10] acute respiratory failure in the immediate post-operative period following extubation [11]; in patients who require orotracheal intubation and mechanical ventilation, NPPV can be used in the "weaning" process [12] and also in patients with respiratory failure who are not suitable for orotracheal intubation [13]. Appropriate patient screening is crucial to ensure the success of NPPV (Table 1) and to prevent use when contraindicated (Table 2). Unlike invasive ventilation, non-invasive techniques do not require an artificial airway (endotracheal tube or tracheostomy). A good interface is essential. Both nasal and oronasal and facial masks can be used. Nasal masks leave the mouth uncovered, enabling the patient to talk and eat, but air loss through the mouth is common. Whatever type is chosen, it should always be a good fit.

Table 1: Patient characteristics favourable for treatment with noninvasive ventilation.

\begin{tabular}{|c|}
\hline Collaborative patient \\
\hline Intact neurological function \\
\hline Capable of coordinating breathing with ventilator \\
\hline Moderate, non-severe disease \\
\hline Teeth intact \\
\hline Capable of controlling oral and pulmonary secretions \\
\hline Moderate hypercapnia \\
\hline Moderate respiratory acidosis (pH $>7.20)$ \\
\hline
\end{tabular}

Table 2: Contraindications to the use of non-invasive ventilation.

\begin{tabular}{|c|}
\hline Need for immediate intubation due to severe respiratory failure \\
\hline Compromised upper airway \\
\hline Swallowing dysfunction \\
\hline Poor elimination of secretions \\
\hline Clinical instability \\
\hline Anatomical abnormality preventing mask adjustment \\
\hline Non-cooperative patients \\
\hline Severe disorder causing respiratory failure
\end{tabular}

Table 3: Complications of no-invasive ventilation.

Poor Mask Tolerance

Result of tight mask seals used to attain adequate inspiratory volumes

Minimize pressure by intermittent application of non-invasive ventilation

Schedule breaks (30-90 min) to minimize effects of mask pressure

Cover vulnerable areas (erythematous points of contact) with protective dressings

\section{Air Loss}

Balance strap tension to minimize mask leaks without excessive mask pressure

Dry Mucous Membranes and Thick Secretions

Provide humidification for noninvasive ventilation devices

\begin{tabular}{|c|}
\hline Provide daily oral care \\
\hline Chest physiotherapy \\
\hline Airway clearance techniques \\
\hline Pneumothorax
\end{tabular}

Hypotension related to positive intrathoracic pressure (support with fluids)

\section{Gastric Distension}

Avoid by limiting peak inspiratory pressures to less than $25 \mathrm{~cm}$ water Nasogastric tubes can be placed but can worsen leaks from the mask

Nasogastric tube also bypasses the lower esophageal sphincter and permits reflux

To facilitate tolerance, it is good idea to initially use low pressure. Initial pressure support could be 4-10 $\mathrm{cm} \mathrm{H}_{2} \mathrm{O}$, PEEP: 2-4 $\mathrm{cm} \mathrm{H}_{2} \mathrm{O}$, inspiratory pressure: 8-12 $\mathrm{cm} \mathrm{H}_{2} \mathrm{O}$ and expiratory pressure: $2-4 \mathrm{~cm} \mathrm{H}_{2} \mathrm{O}$. The initial tidal volume ranges from 10 to $15 \mathrm{ml} / \mathrm{kg}$. As patient tolerance increases, inspiratory pressure or tidal volume can be gradually increased to enable small reductions in $\mathrm{PCO}_{2}(5-10 \mathrm{mmHg})$. If oxygenation is still low, expiratory pressure can be increased. Patients who respond well to the system will present lower respiratory rate, heart rate and PCO2 after a few hours. The possible complications are shown in Table 3. Several studies have shown the efficacy of NPPV for preventing nosocomial pneumonia and other orotracheal intubation complications [14-16]. As these patients are not sedated, complications due to immobilisation are prevented and adequate nutrition is ensured. ICU stays can be prevented. It does, however, have some disadvantages: no airway protection and no direct access to the trachea for aspiration. 


\section{Lung Transplantation}

The first references to lung transplantation date from the 1940s and 1950s, when authors such as Vladimir Demikhov and Dominique Metras demonstrated the viability of the surgical technique in experimental animals [17]. Subsequently, in 1963, James Hardy performed the first single lung transplant in humans. The patient was a death row inmate who had been diagnosed with squamous cell carcinoma in the left lung and emphysema. He only survived for 18 days, and died from kidney failure [18]. Further attempts were made in the following years, but they systematically failed due to infections, graft rejection and problems related to bronchial anastomosis healing. It was not until the 1980s when the Toronto group, under the leadership of Joel Cooper, performed the first successful single (1983) and double (1986) lung transplants, thus establishing the procedure as treatment for end-stage lung diseases [19]. Since then there has been significant progress in both surgical technique and overall patient management, and the procedure can now be safely performed with greater short- and mediumterm survival rates. It is currently a valid therapy for some endstage lung diseases with less than 2 years of life expectancy for which there are no further medical options.

The diseases that most often require this procedure are: emphysema-like COPD with or withoutalpha-1-antitripsin deficit, interstitial diseases such as idiopathic pulmonary fibrosis, septic conditions such as cystic fibrosis or bronchiectasis, and primary pulmonary hypertension. The current trend is to perform double lung transplantation, especially in young patients, as they provide better quality of life and long-term survival, despite greater perioperative morbidity/mortality [20]. During surgery, the airway is routinely intubated with a left-sided double lumen tube that enables independent ventilation of both lungs. Immediately after surgery, patients are ventilated with a standard technique. $\mathrm{FiO}_{2}$ is necessary to maintain the $\mathrm{PO}_{2}$ at over $70 \mathrm{mmHg}$. The tidal volume is $12-15 \mathrm{ml} / \mathrm{kg}$ and PEEP is $5-7.5 \mathrm{~cm} \mathrm{H}_{2} \mathrm{O}$. The patient is extubated when there is adequate gas exchange and mechanical respiration, usually after 24-48 hours. PEEP is not needed in COPD patients who receive a single lung, and a lower tidal volume is used. This reduces hyperinflation of the native lung and minimises compression of the transplanted organ.

Air entrapment by the native lung can cause other problems, such as high airway pressure, $\mathrm{CO}_{2}$ retention and hypotension due to reduced venous return. Volume reduction in the native lung is required in extreme cases to relieve compression in the transplanted organ. Mechanical ventilation is maintained for longer, at least 48-72 hours, in patients with vascular pulmonary diseases who have received a single organ transplant, during which time they are sedated and receive muscle relaxants, remaining in a position in which the native lung is lower, thus maintaining inflation and drainage of the grafted organ. Standard tidal volume is used but PEEP increases to $7.5-10 \mathrm{~cm}$
$\mathrm{H}_{2} \mathrm{O}$. Mechanical ventilation is prolonged in case of primary graft dysfunction, rejection or infection. In these cases a tracheotomy should be performed as soon as possible, making the patient more comfortable, increasing his or her mobility, and enabling oral nutrition.

\section{Use of NPPV in Lung Transplantation}

As with any other type of surgery, respiratory complications can arise in the post-operative period, such as atelectasis, pneumonia, pulmonary oedema and acute respiratory failure due to different causes, including pulmonary thromboembolism. Post-operative respiratory failure can be defined as the need to maintain mechanical ventilation for longer than usual for the surgery in question, or the need to re-intubate an extubated patient [21]. In lung transplantation other specific problems can also arise, such as vascular or airways complications (stenosis, dehiscence), primary graft dysfunction, pneumonia and rejection. Nevertheless, acute respiratory failure is the main cause of post-transplant mortality [22]. Special mention should be made of airway anastomoses, specifically dehiscence. In these cases, either invasive or non-invasive positive pressure can hinder management. In severe cases in which a patient cannot be ventilated because all or most of the tidal volume is lost through dehiscence, the only solution is differential ventilation through a double lumen tube: optimal ventilation in the dehiscence-free lung and ventilation with the lowest possible pressure in the other lung.

Disorders where NPPV can be used have already been mentioned above. NPPV has been described in general surgery for preventing acute post-operative respiratory failure (prophylactic use) or for treatment of this condition when it presents $[23,24]$, and it can be used both with continuous (CPAP) and intermittent positive pressure. The expected benefits are: increased lung gas volume, improved gas exchange, reduced atelectasis, reduced respiratory effort, and circumvention of invasive ventilation. In the case of lung transplantation, use of NPPV to avoid orotracheal intubation in cases of respiratory failure has been reported. A study published in 2000 [14] randomised 40 solid organ recipients (lung, liver or kidney) with acute hypoxemic respiratory failure to be treated with NPPV or conventional therapy. There was a sustained, statistically significant improvement in oxygenation in the NPPV group, with less need for invasive ventilation. The incidence of sepsis was also lower, as was ICU mortality rate, although there was no difference in hospital mortality rate. Another observational study conducted in 2001 [25], in which 21 patients undergoing bilateral lung transplant presented acute respiratory failure after extubation, found that NPPV circumvented the need for endotracheal intubation in $85 \%$ of all cases. Rocco, et al. [25] described a series of 21 patients (18 with cystic fibrosis) who, after undergoing double lung transplant developed respiratory insufficiency requiring ventilation support. 
After being treated with NPPV through a facemask, orotracheal intubation was avoided in 18 patients, who were discharged from the ICU. Of the 3 who required intubation, 1 survived and the other 2 died from septic shock. It has been suggested that NPPV can reduce extra vascular pulmonary fluid and restore pulmonary volume, reducing dyspnoea and respiratory effort. In 2009, Feltraco, [26] reported the use of NPPV for the treatment of refractory hypoxia due to primary graft dysfunction, describing two cases. In general, respiratory support is well tolerated and resolves atelectasis and infiltrates, thereby avoiding orotracheal intubation. The use of NPPV associated with changes from a prone to supine position, or even combined with Trendelenburg, improves the ventilationperfusion ratio, suggesting that it could also be used for other lung conditions, which involve areas of dorsal-basal non-recruit able atelectasis.

High frequency percussive ventilation is a method that can be applied by intubation or a facemask [27]. It is a time-cycled, limited pressure mode of ventilation. Cycles are delivered at high frequency (200-900 cycles per minute) in stages. This gives low volume, high rate ventilation that produces a more uniform gas exchange and better distal ventilation, while facilitating elimination of secretions. High frequencies (300-600 cycles per minute) facilitate oxygenation, while low frequencies (180240) facilitate CO2 elimination. Feltraco [28] described its use, combined with postural changes, in three patients who presented respiratory failure after extubation following double lung transplantation, thereby avoiding re-intubation in all three. Phrenic nerve injuries during lung transplantation can be due to direct damage caused during mediastinal dissection or distension while manipulating the pericardium and hypothermia. After surgery, they can give rise to complications such as atelectasis, pneumonia, hypoxaemia and hypoventilation, increasing duration of mechanical ventilation and ICU admission. NPPV has been reported to reduce this time, and can even be applied outside the ICU [29].

NPPV has also been used during the pre-transplant period. Ventilator dependence has traditionally been considered a relative contraindication for transplantation, as the procedure is associated with a higher mortality rate in such patients [30,31]. The presence of microbial colonisation of the airway increases the risk of post-operative pneumonia. Prolonged immobility can also reduce a patient's physical strength, increasing the risk of post-operative complications. However, up to $3 \%$ of transplants have been performed in the US on ventilator-dependent patients [32]. Ideally, in the case of invasive ventilation, the aim should be to extubate once the patient has overcome exacerbation and perform the transplant when he or she is no longer ventilatordependent. Only in carefully selected cases can transplantation be considered in patients who present progressive, irreversible respiratory failure as the result of the evolution of their condition.
The possibility of transplanting a ventilator-dependent patient is considered when respiratory failure is the result of the irreversible evolution of the underlying condition, and other causes (such as respiratory infection, pulmonary thromboembolism, heart failure, etc.) have been ruled out, providing the surgery can be performed before the onset of the aforementioned complications derived from mechanical ventilation, basically pneumonia and decline in physical status. Pulmonary conditions are the main cause of morbidity-mortality in cystic fibrosis, and the use of NPPV has been reported to prolong the life of end-stage patients until a donor appears, avoiding the complications of invasive ventilation. Efrati, et al. [33] described a series of 9 patients: four successfully underwent transplant and 3 died on the waiting list. The other two were still alive when the paper was published. Significant increase in body mass index, improvement in $\mathrm{pH}$ and $\mathrm{PCO}_{2}$, and better sleeps quality and everyday activities, with no ventilation-related complications, have been reported. Further studies describe the successful use of NPPV while waiting for lung transplant [34-37] particularly in cystic fibrosis patients.

\section{Conclusion}

In the last 30-40 years, important progress in respiratory support has been made due to better understanding of the physiology of breathing, the emergence of new specialists in intensive respiratory care, and technological development. Several alternative respiratory support methods have reduced the complications associated with invasive mechanical ventilation. The diseases that most frequently require lung transplantation are: emphysema-like COPD with or without alpha -1- antitrypsin deficit, interstitial diseases such as idiopathic pulmonary fibrosis, septic diseases such as cystic fibrosis or bronchiectasis and primary pulmonary hypertension. The current trend is to perform double lung transplants, especially in young patients, as they provide better quality of life and long-term survival, despite greater peri-operative morbidity/mortality. In the case of lung transplantation, use of NPPV has been reported as a means of avoiding orotracheal intubation in cases of respiratory failure, and in cases of refractory hypoxia; and several longitudinal, randomised studies have shown its superiority over conventional ventilation.

\section{References}

1. Meltzer SJ, Auer J (1909) Continuous respiration without respiratory movements. J Exp Med 11(4): 622-625.

2. Zwillich CW, Pierson DJ, Creagh CE, Sutton FD, Schatz E, et al. (1974) Complications of assisted ventilation. A prospective study of 354 consecutive episodes. Am J Med 57(2): 161-170.

3. Sullivan CE, Issa FG, Berthon-Jones M, Eves L (1981) Reversal of obstructive sleep apnoea by continuous positive airway pressure applied through the nares. Lancet 1 (8225): 862-865.

4. Hill NS (1993) Noninvasive ventilation. Does it work, for whom, and how? Am Rev Respir Dis 147(4): 1050-1055. 
5. Meduri GU, Conoscenti CC, Menashe P, Nair S (1989) Noninvasive face mask ventilation in patients with acute respiratory failure. Chest 95(4): 865-870.

6. Brochard L, Isabey D, Piquet J, Amaro P, Mancebo, et al. (1990) Reversal of acute exacerbations of chronic obstructive lung disease by inspiratory assistance with a face mask. N Engl J Med 323(22): 15231530.

7. Kramer N, Meyer TJ, Meharg J, Cece RD, Hill NS (1995) Randomized, prospective trial of noninvasive positive pressure ventilation in acute respiratory failure. Am J Respir Crit Care Med 151(6): 1799-806.

8. Brochard L, Mancebo J, Wysocki M, Lofaso F, Conti G, et al. (1995) Noninvasive ventilation for acute exacerbations of chronic obstructive pulmonary disease. N Engl J Med 333(13): 817-822.

9. Meduri GU, Abou-Shala N, Fox RC, Jones CB, Leeper KV, et al. (1991) Noninvasive face mask mechanical ventilation in patients with acute hypercapnic respiratory failure. Chest 100(2): 445-454.

10. Wysocki M, Tric L, Wolff MA, Millet H, Herman B (1995) Noninvasive pressure support ventilation in patients with acute respiratory failure. A randomized comparison with conventional therapy. Chest 107(3): 761-768.

11. Benhamou D, Girault C, Faure C, Portier F, Muir JF (1992) Nasal mask ventilation in acute respiratory failure. Experience in elderly patients. Chest 102(3): 912-917.

12. Nava S, Ambrosino N, Clini E, Prato M, Orlando G, et al. (1998) Noninvasive mechanical ventilation in the weaning of patients with respiratory failure due to chronic obstructive pulmonary disease. A randomized, controlled trial. Ann Intern Med 128(9): 721-728.

13. Freichels TA (1994) Palliative ventilatory support: use of noninvasive positive pressure ventilation in terminal respiratory insufficiency. Am J Crit Care 3(1): 6-10.

14. Antonelli M, Conti G, Bufi M, Costa MG, Lappa A, et al. (2000) Noninvasive ventilation for treatment of acute respiratory failure in patients undergoing solid organ transplantation: a randomized trial. JAMA 283(2): 235-241.

15. Antonelli M, Conti G, Rocco M, Bufi M, De Blasi RA, et al. (1998) A comparison of noninvasive positive pressure ventilation and conventional mechanical ventilation in patients with acute respiratory failure. N Engl J Med 339(7): 429-435.

16. Nourdine K, Combes P, Carton MJ, Beuret P, Cannamela A, et al. (1999) Does noninvasive ventilation reduce the ICU nosocomial infection risk? A prospective clinical survey. Intensive Care Med 25(6): 567-573.

17. Konstantinov IE (1998) A Mystery of Vladimir P. Demikhov: The 50th Anniversary of the First Intrathoracic Transplantation. Ann Thorac Surg 65(4): 1171-1177.

18. Hardy JD, Eraslan S, Webb WR (1964) Transplantation of the lung. Ann Surg 160: 440-448.

19. Toronto Lung Transplantation Group (1986) Unilateral lung transplantation for pulmonary fibrosis. N Engl J Med 314(18): 11401145 .

20. Force SD, Kilgo P, Neujahr DC, Pelaez A, Pickens A, et al. (2011) Bilateral lung transplantation offers better long-term survival, compared with single-lung transplantation, for younger patients with idiopathic pulmonary fibrosis. Ann Thorac Surg 91(1): 244-249.

21. Chiumello D, Chevellard G, Gregoretti C (2011) Non-Invasive ventilation in postoperative patients: a systematic review. Intensive Care Med 37(6): 918-929.
22. Cooper JD, Patterson GA, Trulock EP (1994) Results of single and bilateral lung transplantation in 131 consecutive recipients. Washington University Lung Transplant Group. J Thorac Cardiovasc Surg 107(2): 460-470.

23. Ferreyra G, Long Y, Ranieri VM (2009) Respiratory complications after major surgery. Curr Opin Crit Care 15(4): 342-348.

24.Jaber S, Chanques G, Jung B (2010) Postoperative noninvasive ventilation. Anesthesiology 112(2): 453-461.

25. Rocco M, Conti G, Antonelli M, Bufi M, Costa MG, et al. (2001) Noninvasive pressure support ventilation in patients with acute respiratory failure after bilateral lung transplantation. Intensive Care Med 27(10): 1622-1626.

26. Feltracco P, Serra E, Barbieri S, Persona P, Rea F, et al. (2009) Noninvasive ventilation in prone position for refractory hypoxemia after bilateral lung transplantation. Clin Transplant 23(5): 748-750.

27. Lucangelo U, Fontanesi L, Antonaglia V, Pellis T, Berlot G, et al. (2003) High frequency percussive ventilation (HFPV). Principles and technique. Minerva Anestesiol 69(11): 848-851.

28. Feltraco P, Serra E, Barbieri S, Milevoj M, Michieletto E, et al. (2012) Noninvasive High-Frequency Percussive Ventilation in the Prone Position after Lung Transplantation. Transplant Proc 44(7): 20162021.

29. Berk Y, van der Bij W, Erasmus ME, Wijkstra PJ (2006) Non-invasive ventilation in phrenic nerve dysfunction after lung transplantation: an attractive option. J Heart Lung Transplant 25(12): 1483-1485.

30.American Thoracic Society (1998) International guidelines for the selection of lung transplant candidates. Am J Respir Crit Care Med 158(1): 335-339.

31. Hosenpud JD, Bennett LE, Keck BM, Boucek MM, Novick RJ (2001) The Registry of the International Society for Heart and Lung Transplantation: eighteenth official report. J Heart Lung Transplant 20(8): 805-815.

32. O’Brien G, Criner GJ (1999) Mechanical Ventilation as a Bridge to Lung Transplantation. The Journal of Heart and Lung Transplantation 18(3): 255-265.

33. Efrati O, Modan-Moses D, Barak A, Boujanover Y, Augarten A (2004) Long-term non-invasive positive pressure ventilation among cystic fibrosis patients awaiting lung transplantation. Isr Med Assoc J 6(9): 527-530.

34. Quaranta AJ, Roy B, O’Brien G, Kreimer DT, Krachman S, et al. (1996) Noninvasive positive pressure ventilation as bridge therapy to lung transplantation or volume reduction surgery. J Resp Crit Care Med 153(4): A608.

35. Piper AJ, Parker S, Torzillo PJ, Sullivan CE, Bye PT (1992) Nocturnal nasal IPPV stabilizes patients with cystic fibrosis and hypercapnic respiratory failure. Chest 102(3): 846-850.

36. Hobson ME, Madden BP, Steven MH, Tsang VT, Yacoub MH (1991) Noninvasive mechanical ventilation for cystic fibrosis patients: a potential bridge to transplantation. Eur Resp J 4(5): 524-527.

37. Felten ML, Moyer JD, Dreyfus JF, Marandon JY, Sage E, et al. (2016) Immediate postoperative extubation in bilateral lung transplantation: predictive factors and outcomes. Br J Anaesth 116(6): 847-854. 
Your next submission with Juniper Publishers will reach you the below assets

- Quality Editorial service

- Swift Peer Review

- Reprints availability

- E-prints Service

- Manuscript Podcast for convenient understanding

- Global attainment for your research

- Manuscript accessibility in different formats

( Pdf, E-pub, Full Text, audio)

- Unceasing customer service

Track the below URL for one-step submission https://juniperpublishers.com/online-submission.php 